\title{
The Transformation of Police Training in the View of Policing Revolution
}

\author{
Qin Wei \\ Department of Security Administration \\ Hubei University of Police \\ Wuhan, Hubei, China 430034
}

\begin{abstract}
The current policing revolution in China is a comprehensive and systematic reform. The construction of modern policing operation mechanism and police classification management is an important content of reform. Police training also faces corresponding reform and innovation. In particular, it is necessary to strengthen the leading role of policing actualization in police training. This paper promotes the training of police and improves the overall quality and combat capability of the police force through the study of the prominent problems that hinder the development of the police training work from the "five transformations" of "training concept", "management mode", "training content", "training effect" and "guarantee mode".
\end{abstract}

Keywords—policing revolution; police training; transformation

\section{INTRODUCTION}

Over the past three years, China's high-level government has repeatedly stressed the comprehensive deepening of reform, and comprehensive rule of law, which also contributed to the fifth policing revolution of China's police force. There are some problems of inadaptation in the construction of police force, and the reform is also forced to arise by the problem. Education and training of police officers is an important way to train police personnel, also a reliable guarantee for the development of team. It is necessary to pay attention to the core element, the police, to excavate the potential of the police lengthways, strengthen professional skills, enhance the police's working performance, and achieve effective training and management of "improvement without increase of police force". It needs to think about how the education and training serves the development of real work and meets the needs of front-line combat. As a police education and training department, we must follow the requirements of scientization, standardization, informatization and actualization, achieve the "five transformations" of "training concept", "management mode", "training content", "training effect" and "guarantee mode", promote the training of police and enhance the overall quality and combat capability of the police force.

\section{The TRAINING THEORY TRANSFORMS FROM THE "TASK-BASED" TO "ACTUAL COMBAT"}

In recent years, with the rapid development of the current

Project Source: Project of Hubei University of Police [Hubei University of Police (2015) No. 59], Project number: 2015B19, Project name: Study on differentiation model of the police training system under the view of police reform social economy, the social situation is becoming increasingly complex, all kinds of police face arduous work tasks, and many police are under work overload in peace time, besides, the completion assessment training is mostly "going through the motions" without rigid evaluation indicators constraints, Therefore, especially in the closed centralized training, the training organizational unit will take the training work as the annual routine work, once it's completed according to the required time node, thematic content and participant number, the training work is regarded as to have successful conclusion. At the same time, most police who join in training take it as a "resort-style" recreation to ease the pressure and adjust the mentality, so they do not threw them into it. The core intentions such as what the training is for and what kind of effects the training wants to achieve are gradually ignored and forgotten by the training organizers and trainees. The deviation of concept leads to the deviation of training purpose from the training quality and effect. Therefore, we need to clarify the concept of police training, not to complete the task, but to really enhance the police's professional accomplishment and ability when facing the actual combat, so the training should be organized scientifically following the basic principles of "facing the actual combat, paying attention to practicability, focusing on actual effect". The training organization shall adhere to the training concept of "combining peacetime and wartime, combining fight and training", with standardized management and actualization guidance, organically combine "individual and group, strategy and tactics, combined training and separate training", and effort to build and train all kinds of police professionals.

\section{The MANagement Mode Transforms From the \\ "ADMINISTRATIVE DECISION-MAKING" TO "AUTONOMOUS TRAINING"}

At present, the basic teaching management links such as instructor assignment for police training in all provinces, training course setting, training duration and training content ratio are decided by the Education and Training Office of the Political Department of Provincial Police Agency, which inevitably has much administrative decision-making color, but it does not mean that the training management mode should exclude the administrative decision-making. On the contrary, it indicates that it is necessary to enhance the administrative level, handle the relationship between the administrative and educational roles, scientifically and rationally define their 
respective positions, so that the administrative contents return to administration, and the educational contents return to education, form positive interaction between the efficient administration and scientific training, rather than dislocate which leads to chaos of the training mechanism. It is necessary to clarify the autonomy of the provincial police training center based on the advantageous police education base, the police academy, in the links of training and education in police training in the whole province, so as to avoid indirectness and non-strength of the training executing department in training quality control for it only has the executive power but no decision-making power in training links, whose negative result will directly lead to realistic problems such as the lag, repeatability and extensiveness of the training content, the decentralization of the trainees control, the formalization of training assessment, and the deviation of training effect.

\section{THE TRAINING CONTENT TRANSFORMS FROM THE "THEORETICAL" TO "PRACTICAL"}

We should abandon "spoon-feeding", "cramming" and "airto-air" traditional teaching which focuses on class, centers on teacher and is driven by indoctrinization, replace with new teaching mode which pays equal attention to class and practice, focuses on practice, centers on learner, and is driven by research. "Soldiers shall be trained like they are in the war", the education and training should focus on the grassroots level, and serve the combat, and make sure to "train police carefully" to achieve "training elite troops and strong general". Firstly, go down to the grassroots level, do a good job in research, enhance the pertinence of teaching and training. Organize the instructors to go down to the grassroots level and to the front line, to understand the basic work practice, master the thinking of grassroots police, find the most urgent problems of thinking, law and skills in grassroots work, so as to determine the center training content according to the reality, improve pertinence of training. Secondly, we should pay attention to the demand, classify and implement to enhance the systematicness of teaching and training. In accordance with the principle of "priority to the emergent and the easy, step by step", we will formulate corresponding training norms and standards for training of different police classification, posts and properties, and form a police training course system with clear target and distinct features, to maximally satisfy the learning need of different classes and levels of police. Thirdly, close to actual combat, combine civil and military skills, enhance the practicality of teaching and training. On the one hand, pay attention to the application of laws and regulations in actual combat, and promote to strictly act by law; on the other hand, strengthen the police's combat skill training. Sweat more in peacetime to bleed less in wartime, exercise repeatedly, master skillfully, act in perfect unison to win the victory over the enemy, to "be able to fight, chase and win" in dealing with emergency and maintaining stability, and become new force with swift response and flexibility. Fourthly, base on their own positions, train according to post, enhance the normality of teaching and training. Implement combination of fighting and training, during training period, train in the day and patrol at night. Establish of normalized post training mechanism, set conditions according to the teaching needs, select the best candidate. Take outstanding professional ability, actual operational experience, flexible teaching methods and excellence in language expression as a major condition, through the links of police self-recommendation, unit recommendation, business contest, trial teaching and evaluation, select and employ different police classifications all over the province as part-time instructor for various professions, responsible for theory teaching, employ once a year, reserve instructor force. Combined with the instructor's teaching quality, student evaluation, teaching result and working attitude, an assessment is implemented once a year to timely adjust incompetent personnel. At the same time, actively recommend instructors to participate in instructor training courses organized by the police organs for "further study" to improve the professional quality of instructors. Take various flexible forms of training instructor, attachment and dispatch and delivering teaching home to carry out job training and achieve "learning as working and working as learning." We should give full play to the advantages of social resources, introduce the teaching force in the society to assume the teaching tasks of some subjects. On the one hand, excavate external and social resources, select and employ experienced experts scholars, professors, etc. with high- theory level to enrich the instructor force. On the other hand, employ full-time policing skill instructors of policing theory from the most front line and from the talent pool of instructors resources in the whole province, optimize the allocation of resources to improve the quality of training.

\section{The TrAinING EFFECT TRANSFORMS FROM "SINGLE" TO "COMPOUND"}

The effect of education and training is the "touchstone" to test the success of education and training. Firstly, reasonably arrange courses, combine theory with practice. Center on the target of "realistic, practical and effective" in course setting, implement three "one-thirds", namely one third of the time for theoretical study of politics, laws and policing; one third of the time for comprehensive exercises of physical agility, skill, investigation and seizing tactics; and one third of the time foe the implementation of "combining fight and training" and application of informatization. Secondly, reform the teaching methods, due to constraints of factors like poor teaching conditions, lack of instructors and their professional skills, the traditional Chinese-style teaching mode, namely instructororiented mode is still mainly adopted in teaching, yet the interactive, heuristic and situational teaching is hardly used, let alone achieve one-on-one teaching, and the situation in which the police forget after learning has occurred from time to time. The training should be closer to actual combat, highlight actual combat, serve the actual combat, pay attention to combining fight and training, flexibly teach, pursue effective teaching methods, so as to combine preaching and exercise. We should carry out the principle of "teaching only the essential and ensuring plenty of practice", change the single theoretical teaching method, implement the new teaching method such as research style, case style, interactive style, analogical style and situational style, and fully mobilize the participation and enthusiasm of the trainees. Thirdly, enhance the training effect, combine the professional skills with comprehensive quality. According to the needs of police duties, based on the principle of training what is doing, supplementing what is lacking, 
fourthly, carry out track management, combine learning and practice. Implement track management on the police passing the training, understand the application of the knowledge learned in policing training to the practical work, complement each other, and urge the police to combine "learning" and "practice" to achieve the purpose of education and training.

\section{THE TRAINING GUARANTEE TRANSFORMS FROM THE "REAL" TO "DEVELOPMENTAL"}

Strengthen the construction of mechanisms to ensure the leapfrog development of education and training. Firstly, strengthen the construction of hardware and software. Make full use of various resources and effectively solve the training venue and equipment, at the same time, start from the longterm perspective, take the initiative to strengthen communication and contact with departments at all levels to obtain support, make the policing practice base bigger and stronger, improve training facilities, create better conditions for police training. In addition, with the optimization of police's education background and overall improvement of comprehensive qualities and abilities, the police's demand of the quality and form of training materials also improves, but the police organs lack authoritative, professional and practical teaching materials, and the instructors are using their own experience as teaching materials, the content of which is limited to police skills, laws and regulations, and materials involving police working methods, public opinion control and guidance, application of informatization, anti-terrorism and other aspects are used relatively less or not, making it difficult to meet practical needs of work.

Secondly, strengthen the guarantee of discipline. Establish and improve reward and punishment mechanism of education and training assessment, and strive to form a strong atmosphere of competition. Train strictly, manage strictly, and test strictly, implement militarized management and one-day life system, adhere to the separation of examination and training, test both theory and skills, both results and actual performance, trainees with poor performance during training, person graded last shall be eliminated in a proportion. If passing the training, we take it as the standard for police to obtain job qualification and promotion, and if getting excellent in the training, we take it as precondition of award-winning and promotion. Only by establishing a clear direction can the trained police have both pressure and motivation. Thirdly, strengthen funding security. Further clarify the special funds for police education and training, include education and training funds in the annual budget, establish a fund management system with full sharing, appropriate base, dynamic growth and strong supervision according to the actual situation, and form a reasonable fund, special fund for special purpose, to guarantee the normal operation of work.

\section{CONCLUSION}

At present, the optimization and transformation of police training is the fundamental way to improve the combat effectiveness of the police force, which is has leading, basic and strategic position in the policing reform, and the exploration of how to transform the police training is to improve the overall quality and law enforcement level, enhance their ability to fulfill their duties, create honest and clean police force with firm conviction, which enforces the law for peoples and dare to play. Therefore, perfecting and innovating the current police revolution, the police training mechanism under the great background, is a necessary requirement to implement the new "People's Police Law" and enhance the level of law enforcement and actual combat capability of the police force.

\section{REFERENCES}

[1] Xin Min. Interview with the United States criminal expert, Dr. L Changyu [J]. Police Education, 2001, (4).

[2] Zhang Chunlu.Construction of the "people-oriented" police training model $[\mathrm{J}]$.Police combat training research, 2012, (4).

[3] Li Lihong. Prominent problems in police training and countermeasures [J]. Police Research, 2006, (1). 